\title{
Hubungan Tinggi Badan Ibu dan Riwayat Pemberian MP-ASI dengan Kejadian Stunting pada Balita Usia 24-59 Bulan
}

\section{The Relationship between Maternal Stature and Complementary Feeding History with the Incidence of Stunting on Age 24-59 Months' Children}

\author{
Nur Hadibah Hanum*1
}

ABSTRAK

Latar Belakang: Stunting merupakan keadaan tubuh pendek akibat dari kekurangan asupan berbagai macam zat gizi. Ukuran tubuh ibu mungkin menjadi salah satu faktor penyebab terjadinya stunting pada anak.

Tujuan: Tujuan penelitian ini untuk menganalisis hubungan antara tinggi badan ibu dan riwayat pemberian makanan pendamping air susu ibu (MP-ASI) dengan kejadian stunting pada balita usia 24-59 bulan.

Metode: Menggunakan cross sectional dilakukan di Kecamatan Maron Kabupaten Probolinggo. Pengambilan sampel dilakukan secara multistage random sampling dengan besar sampel 97 ibu-balita. Variabel bebas yang diamati antara lain tinggi badan ibu dan riwayat pemberian MP-ASI yang terdiri dari usia pertama kali diberikan makanan, bentuk, frekuensi, dan jumlah MP-ASI sedangkan variabel tergantung adalah kejadian stunting. Analisis data yang digunakan adalah uji chisquare.

Hasil: Hasil penelitian menunjukkan bahwa terdapat hubungan yang bermakna antara pemberian makanan pendamping ASI pada usia pertama kali diberikan makanan yaitu sebelum, saat, atau sesudah bayi berusia 6 bulan dengan kejadian stunting $p=0,012$ sebaliknya tidak ada hubungan antara bentuk $p=0,788$, frekuensi $p=0,208$, jumlah $p=0,107$ dan tinggi badan ibu $p=0,704$, dengan kejadian stunting.

Kesimpulan: Kesimpulan dari penelitian ini adalah riwayat pemberian MP-ASI pada faktor usia balita pertama kali diberikan MP-ASI berhubungan dengan kejadian stunting pada balita, sedangkan bentuk, frekuensi, jumlah makanan yang diberikan serta tinggi badan ibu balita tidak memiliki hubungan dengan kejadian stunting.

Kata kunci: stunting, tinggi badan Ibu, MP-ASI

\section{ABSTRACT}

Background: Stunting is a short body condition that occurs due to a lack of intake of various nutrients. Maternal body size may be one of the factors causing stunting in children.

Objective: The purpose of this study was to analyze the relationship between maternal height and complementary feeding history with The Incidence of Stunting on Age 24-59 months.

Methods: The cross-sectional study was carried out in Maron District, Probolinggo Regency. The sampling was carried out by multistage random sampling method with a sample of 97 pairs of mothers and under five years old children. Independent variables observed were maternal stature and complementary feeding history which consists of the age of first given food, complementary feeding texture, frequency, and amount of complementary food given. The dependent variable was the occurrence of stunting. Data analysis used in this study was chi-square test.

Results: This study shows the results of a significant association between complementary feeding at the age of first given food at the age of first given food that is before, during, or after a 6 month old with the incidence of stunting $p=0.012$. On the other hand, there was no correlation between complementary feeding texture $p=0.788$, frequency $p=0.208$, amount of complementary food given $p=0.107$, and maternal height $p=0.704$ with the incidence of stunting.

Conclusion: In conclusion, complementary feeding history was related to the incidence of stunting in infants, whereas complementary feeding texture, frequency, amount of complementary food and maternal height had no impact on the incidence of stunting in infants.

Keywords: maternal stature, stunting, complementary feeding 


\author{
*Koresponden : \\ nurhadibah2016@gmail.com \\ ${ }^{1}$ Departemen Gizi Kesehatan, Fakultas Kesehatan Masyarakat, Universitas Airlangga \\ Kampus C Mulyorejo, 60115, Surabaya, Jawa Timur, Indonesia
}

\section{PENDAHULUAN}

Masalah gizi utama yang dihadapi negara berkembang adalah Stunting ${ }^{1}$. Menurut Balitbangkes RI (2010), Stunting merupakan kondisi tubuh yang pendek dan sangat pendek mencapai -2 SD di bawah median panjang atau tinggi badan populasi yang menjadi referensi international. Kondisi ini terjadi akibat dari faktor manusia yang didukung oleh kekurangan asupan berbagai zat gizi. Stunting juga dapat berakibat buruk bagi kelangsungan hidup anak yaitu adanya gangguan pertumbuhan linear yang disebabkan ketidakcukupan asupan zat gizi kronis dan atau penyakit infeksi kronis maupun berulang ${ }^{2}$.

Prevalensi stunting Nasional tahun 2013 mencapai 37,2\% ${ }^{3}$. Angka ini meningkat dari tahun 2010 sebesar 35,6\% dan tahun 2007 sebesar 36,8\%4. Prevalensi stunting di Indonesia tergolong tinggi karena melebihi cut off point yang ditetapkan oleh WHO tahun $2005(\geq 20 \%)^{2}$. Jawa Timur memiliki prevalensi stunting sebesar $35,8 \%$, lebih rendah dibanding prevalensi di Indonesia (37,2\%). Salah satu dari 11 Kabupaten atau Kota di Jawa Timur yang termasuk dalam intervensi stunting adalah Kabupaten Probolinggo, dan pada tahun 2013 memiliki prevalensi stunting sebesar 49,43\%5. Kabupaten Probolinggo mengalami masalah kesehatan yang dianggap berat sehingga perlu diperhatikan dalam bidang kesehatan masyarakat.

Kejadian stunting berdampak pada peningkatan mortalitas dan morbiditas, penurunan perkembangan kognitif, motorik, bahasa, dan meningkatnya pengeluaran untuk biaya kesehatan, tinggi badan yang pendek, Resiko obesitas dan komorbidnya yang meningkat, serta kesehatan reproduksi yang menurun, penurunan kecerdasan dan kapasitas belajar, penurunan kemampuan dan kapasitas kerja ${ }^{6}$. Menurut WHO (2013), Beberapa faktor penyebab terjadinya kejadian stunting pada anak ada 4 kategori besar yaitu 1) Rumah tangga dan keluarga, 2) Kurangnya makanan tambahan atau komplementer, 3) Pemberian ASI, dan 4) Faktor infeksi. Faktor dalam rumah tangga dan keluarga diantaranya tinggi badan ibu yang rendah dan Intra Uterine Growth Retardation (IUGR) yang dapat menyebabkan kejadian BBLR karena adanya gangguan aliran darah pada rahim dan gangguan pertumbuhan uterus, plasenta dan janin pada ibu hamil yang pendek atau terbatas sehingga bayi terlahir dengan berat badan rendah?

Pengaruh ibu yang pendek terhadap kejadian stunting pada anak ditunjukkan oleh hasil penelitian Sumarmi (2016) di 9 kecamatan se-Kabupaten Probolinggo termasuk pada Kecamatan Maron bahwa seorang ibu pendek kemungkinan besar akan melahirkan bayi pendek atau stunting yang mencerminkan kekurangan gizi antar generasi dari ibu untuk bayi mereka ${ }^{8}$.
Namun penelitian tersebut tidak meneliti apakah bayi yang pendek akan tumbuh menjadi balita yang pendek atau tidak. Kejadian stunting tersebut perlu diputuskan segera pada siklus balita stunting intergenerasi agar kejadian ibu pendek tidak melahirkan bayi yang pendek lagi.

Bayi yang wajib diberi ASI saja adalah bayi yang baru lahir sampai dengan usia 6 bulan, tanpa diberikan makanan tambahan lain, namun, setelah bayi berusia 6 bulan, bayi perlu diberikan makanan tambahan selain ASI. Faktor lain penyebab kejadian stunting adalah pemberian makanan tambahan yang tidak adekuat, dalam hal ini adalah memberikan makanan pendamping ASI (MP-ASI). MP-ASI yang diberikan terlambat bisa mengakibatkan bayi mengalami kekurangan zat besi oleh karena tidak mendapat cukup zat gizi ${ }^{6}$. Terhambatnya pertumbuhan pada anak akibat kurangnya asupan zat besi pada masa balita tesebut apabila berlangsung dalam waktu yang cukup lama akan berakibat stunting ${ }^{9}$, maka perlu memperhatikan pemberian MP-ASI agar gizi balita tercukupi.

Tujuan dari penelitian ini adalah menganalisa hubungan tinggi badan ibu dan MP-ASI dengan kejadian stunting pada balita usia 24-59 bulan di Kecamatan Maron Kabupaten Probolinggo.

\section{METODE}

Penelitian dengan desain cross sectional, dilaksanakan pada bulan Juli hingga Agustus 2018 di wilayah Puskesmas Maron Kecamatan Maron Kabupaten Probolinggo, yang menjadi populasi adalah seluruh balita usia yang 24-59 bulan di Kecamatan Maron Kabupaten Probolinggo. Populasi yang dipilih sebanyak 337 balita dilakukan secara multistage random sampling. Sampel yang digunakan pada studi ini adalah balita usia 24-59 bulan yang ada di Kecamatan Maron Kabupaten Probolinggo. Besar sampel sebanyak 97 pasang ibubalita dengan kriteria 1) Ibu balita bersedia menjadi responden dan bersedia memberikan data yang dibutuhkan terkait penelitian secara lengkap; 2) Ibu balita yang menjadi responden hanya memiliki 1 balita saja; 3) Responden memiliki buku KIA; 4) Balita tidak sedang menderita penyakit bawaan lahir.

Tinggi badan ibu dan riwayat pemberian makanan pendamping air susu ibu yang meliputi usia bayi saat pertama kali mendapatkan makanan tambahan, frekuensi, jumlah, tekstur, variasi, respon anak dan kebersihan peralatan serta bahan makanan yang akan diberikan pada anak merupakan variabel bebas sedangkan variabel tergantungnya kejadian stunting. Data tinggi badan ibu dan tinggi badan balita diperoleh dari pengukuran menggunakan alat ukur tinggi badan microtoise. Tinggi badan ibu dikategorikan menjadi pendek $<150 \mathrm{~cm}$ dan tidak pendek $\geq 150 \mathrm{~cm}$. 
Status stunting balita diperoleh dengan mengukur tinggi badan dibandingkan umur dalam bulan kemudian dilakukan penentuan status stunting balita. Data riwayat MP-ASI diperoleh dengan wawancara pada responden dengan bantuan kuesioner. Kuesioner ini terdiri dari 3 jenis pertanyaan meliputi usia bayi saat pertama kali mendapatkan makanan tambahan, frekuensi dan jumlah makanan yang akan diberikan pada anak. Data riwayat MP-ASI berdasarkan usia diperoleh dari kuesioner hasil wawancara langsung pada responden, usia pemberian MP-ASI dikategorikan menjadi 2 : 1) Tepat, jika makanan pertama kali diberikan saat usia 6 bulan; 2) Tidak Tepat, jika makanan pertama kali diberikan saat usia $<6$ bulan atau $>6$ bulan ${ }^{10}$.

Jumlah MP-ASI yang diberikan dikategorikan menjadi $2: 1$ ) Tepat, jika jumlah MP-ASI diberikan sesuai standart, a) Untuk usia 6-8 bulan 2-3 sdm penuh tiap kali makan, b) Untuk usia 9-11 bulan $1 / 2$ mangkok ukuran $250 \mathrm{ml}$, c) Untuk $12-24$ bulan $3 / 4$ mangkok ukuran $250 \mathrm{ml}$; 2) Tidak Tepat, jika jumlah MP-ASI diberikan tidak sesuai standart ${ }^{10}$

Frekuensi pemberian MP-ASI dikategorikan menjadi 2 : 1) Tepat, jika frekuensi makan diberikan sesuai standart yaitu a) Untuk usia 6-8 bulan 2-3 kali makanan lumat dan 1-2 kali selingan, b) Untuk usia 9-11 bulan 3-4 kali makanan lembik dan 1-2 kali selingan, c) Untuk 12-24 3-4 kali makanan keluarga dan 1-2 kali selingan; 2) Tidak Tepat, jika frekuensi makan diberikan tidak sesuai standart ${ }^{10}$.

Jumlah MP-ASI yang diberikan dikategorikan menjadi 2 : 1) Tepat, jika jumlah MP-ASI diberikan sesuai standart, a) Untuk usia 6-8 bulan 2-3 sdm penuh tiap kali makan, b) Untuk usia 9-11 bulan 1/2 mangkok ukuran $250 \mathrm{ml}$, c) Untuk 12-24 bulan $3 / 4$ mangkok ukuran $250 \mathrm{ml}$; 2) Tidak Tepat, jika jumlah MP-ASI diberikan tidak sesuai standart ${ }^{10}$.

Uji chi-square melalui SPSS 21 digunakan untuk menganalisa data. Uji chi-square digunakan untuk mengetahui korelasi antara satu variabel bebas dengan variabel terikat dan untuk mengetahui arah hubungan dan kuat lemah hubungan antar variabel. Nilai hasil uji chi-square yang diinterpretasi pada penelitian ini adalah nilai $p$-value, OR (odd ratio) dan $r$ (nilai Contingency Coefficient).

Uji etik tentang penelitian ini sudah disetujui oleh komisi etik Fakultas Kesehatan Masyarakat Universitas Airlangga Surabaya pada tanggal 13 Juli 2018 dengan nomor 391/KEPK.

\section{HASIL DAN PEMBAHASAN}

Karakteristik responden (ibu balita) meliputi usia ibu, pendidikan ibu, pekerjaan ibu, dan tinggi badan ibu. Usia ibu dikategorikan menjadi 2 yaitu kurang dari 20 tahun atau diatas 35 tahun dan usia antara 20 sampai dengan 35 tahun. Karakteristik responden disajikan pada Tabel 1.

Penelitian ini menunjukkan hasil sebagian besar responden berada pada usia 20-35 tahun $(71,1 \%)$, usia responden (ibu balita) rata-rata 31,91 tahun. Tingkat pendidikan responden sebagian besar berada pada jenjang pendidikan SMA/Sederajat (35,1\%), Status pekerjaan responden sebagian besar adalah IRT/ Tidak bekerja $(73,2 \%)$ dan tinggi badan ibu paling banyak pada kelompok ibu yang tidak pendek yaitu sebesar $70,1 \%$. Rata-rata tinggi badan ibu balita $152,2 \mathrm{~cm}$ dengan nilai terendah $138 \mathrm{~cm}$ dan tertinggi $165 \mathrm{~cm}$ serta std. Deviasinya $4,9706 \mathrm{~cm}$.

Masa produktif seseorang, masa madya atau dewasa yang merupakan masa dimana seseorang mudah menerima proses belajar dan perkembangan daya intelektualnya terdapat pada rentang usia 20-35 tahun ${ }^{11}$. Responden pada usia 20-30 tahun mempunyai cukup pengalaman dan cara berfikir yang semakin berkembang dan pengetahuan tentang cara pemberian makanan pendamping ASI yang baik bagi bayinya ${ }^{12}$.

Tabel 1. Karakteristik Responden (ibu balita) di Wilayah Kerja Puskesmas Maron Tahun 2018

\begin{tabular}{|c|c|c|}
\hline \multirow{2}{*}{ Karakteristik } & \multicolumn{2}{|c|}{ Jumlah Responden $(n=97)$} \\
\hline & $\mathrm{n}$ & $\%$ \\
\hline \multicolumn{3}{|l|}{ Usia Ibu } \\
\hline$<20$ tahun atau $>$ & 28 & 28,9 \\
\hline 35 tahun & 69 & 71,1 \\
\hline 20-35 tahun & & \\
\hline \multicolumn{3}{|l|}{ Tingkat Pendidikan } \\
\hline $\begin{array}{l}\text { Tidak sekolah } \\
\text { tidak tamat SD }\end{array}$ & 1 & 1,0 \\
\hline Lulus SD/Sederajat & 21 & 21,6 \\
\hline Lulus & & \\
\hline $\begin{array}{l}\text { SMP/Sederajat } \\
\text { Lulus }\end{array}$ & 22 & 22,7 \\
\hline $\begin{array}{l}\text { SMA/Sederajat } \\
\text { Lulus }\end{array}$ & 34 & 35,1 \\
\hline Diploma/Sarjana & 19 & 19,6 \\
\hline \multicolumn{3}{|l|}{ Pekerjaan } \\
\hline PNS & 13 & 13,4 \\
\hline Pegawai Swasta & 7 & 7,2 \\
\hline Wiraswasta & 5 & 5,2 \\
\hline Buruh & 1 & 1 \\
\hline Tidak Bekerja / IRT & 71 & 73,2 \\
\hline \multicolumn{3}{|l|}{ Tinggi Badan Ibu } \\
\hline Pendek & 29 & 29,9 \\
\hline Tidak Pendek & 68 & 70,1 \\
\hline
\end{tabular}

Ibu yang berpendidikan tinggi, biasanya lebih mudah mengalami perubahan berperilaku dalam memelihara kesehatan. Tingkat pendidikan keluarga khususnya pendidikan ibu dapat menjadi faktor yang berpengaruh terhadap status gizi anak dan keluarga. Anak yang kurang gizi bisa juga karena perhatian orang tua terhadap gizi anak yang kurang. Hal ini karena rendahnya pengetahuan gizi ibu. Pengetahuan gizi tersebut dipengaruhi oleh pendidikan formal ibu yang mempengaruhi perubahan perilaku kesehatan untuk lebih peduli terhadap gizi anak dan keluarga ${ }^{13}$.

Responden di wilayah kerja Puskesmas Maron sebagian besar memiliki tinggi badan yang tidak pendek yaitu sebesar $70,1 \%$ sedangkan yang pendek sebesar $29,9 \%$. Ibu pendek yang memiliki tinggi badan $<150 \mathrm{~cm}$ mempunyai peluang lebih besar melahirkan bayi yang pendek/stunting sebesar 2,04 kali daripada ibu dengan 
tinggi badan $>150 \mathrm{~cm}^{14}$. Hal ini karena aliran darah rahim dan pertumbuhan uterus, plasenta dan janin pada ibu hamil pendek terbatas sehingga bayi yang dilahirkan memiliki berat badan rendah, sehingga perlu dilakukan perbaikan terhadap terjadinya perlambatan atau retardasi pertumbuhan janin yang dikenal sebagai IUGR (Intra Uterine Growth Retardation) dan berat bayi lahir rendah $(B B L R)^{7}$. Kejadian ini akan berlangsung di generasi selanjutnya, masalah anak pendek antar generasi tidak bisa dihindari kecuali ada perbaikan gizi dan pelayanan kesehatan yang memadai pada masamasa tersebut.

Karakteristik balita meliputi usia balita, jenis kelamin, berat badan lahir, dan tinggi badan. Usia balita adalah lama hidup balita dari lahir sampai dilakukan penelitian yang dihitung berdasarkan tanggal kelahiran dalam satuan bulan. Karakteristik balita disajikan pada Tabel 2.

Berdasarkan Tabel 2 dapat dilihat bahwa usia balita stunting pada penelitian ini sebagian besar berada pada rentang usia $36-47$ bulan $(51,7 \%)$. Tingginya kejadian balita stunting pada usia 36-47 bulan dapat menggambarkan adanya kegagalan pertumbuhan (stunted $)^{15}$.

Hasil penelitian di wilayah Kecamatan Maron menemukan bahwa berdasarkan jenis kelamin, proporsi stunting terbesar terdapat pada kelompok balita laki-laki (52,3\%). Hal ini sesuai dengan penelitian yang dilakukan di NTT bahwa balita stunting banyak ditemukan pada anak laki-laki ${ }^{16}$. Hal ini berkaitan dengan asupan makan seperti yang dinyatakan oleh Purwaningrum dan Wardani (2012) dalam penelitiannya bahwa jenis kelamin akan mempengaruhi asupan makan yang dikonsumsi, jenis kelamin laki-laki asupan makan yang dikonsumsi lebih banyak dibandingkan dengan jenis kelamin perempuan ${ }^{17}$. Pada tahun pertama kehidupan laki-laki lebih rentan mengalami masalah gizi dari pada anak perempuan, karena ukuran tubuh laki-laki yang lebih besar sehingga membutuhkan asupan energi yang lebih besar. Apabila asupan makan tidak terpenuhi dan kondisi tersebut terjadi dalam jangka waktu yang lama maka akan mengganggu pertumbuhan ${ }^{18}$.

Tabel 2. Distribusi Balita Berdasarkan Usia Balita, Jenis Kelamin, Berat Badan Lahir dan Tinggi Badan Balita di Wilayah Kerja Puskesmas Maron Tahun 2018

\begin{tabular}{|c|c|c|c|c|c|c|}
\hline \multirow{3}{*}{ Karakteristik Balita } & \multicolumn{4}{|c|}{ Status Stunting Balita } & \multirow{2}{*}{\multicolumn{2}{|c|}{ Total }} \\
\hline & \multicolumn{2}{|c|}{ Stunting } & \multicolumn{2}{|c|}{ Tidak Stunting } & & \\
\hline & $\mathbf{n}$ & $\%$ & $\mathbf{n}$ & $\%$ & $\mathbf{n}$ & $\%$ \\
\hline \multicolumn{7}{|l|}{ Usia (bulan) } \\
\hline 24-35 & 16 & 35,6 & 29 & 64,4 & 45 & 100 \\
\hline $36-47$ & 15 & 51,7 & 14 & 48,3 & 29 & 100 \\
\hline 48-59 & 8 & 34,8 & 15 & 65,2 & 23 & 100 \\
\hline \multicolumn{7}{|l|}{ Jenis Kelamin } \\
\hline Laki-laki & 23 & 52,3 & 21 & 47,7 & 44 & 100 \\
\hline Perempuan & 16 & 30,2 & 37 & 69,8 & 53 & 100 \\
\hline \multicolumn{7}{|l|}{ Berat Badan Lahir } \\
\hline BBLR & 4 & 26,7 & 11 & 73,3 & 15 & 100 \\
\hline Tidak BBLR & 35 & 42,7 & 47 & 57,3 & 82 & 100 \\
\hline
\end{tabular}

Tabel 3. Distribusi Balita Berdasarkan Riwayat Pemberian MP-ASI dan Status Stunting Balita di Wilayah Kerja Puskesmas Maron Tahun 2018.

\begin{tabular}{|c|c|c|c|c|c|c|c|c|}
\hline \multirow{3}{*}{$\begin{array}{c}\text { Pemberian } \\
\text { MP-ASI }\end{array}$} & \multicolumn{4}{|c|}{ Status Stunting Balita } & \multirow{2}{*}{\multicolumn{2}{|c|}{ Total }} & \multirow{3}{*}{$\begin{array}{l}P \text { Value } \\
\left(x^{2}\right)\end{array}$} & \multirow[b]{3}{*}{ OR } \\
\hline & \multicolumn{2}{|c|}{ Stunting } & \multicolumn{2}{|c|}{ Tidak Stunting } & & & & \\
\hline & $\mathbf{n}$ & $\%$ & $n$ & $\%$ & $\mathbf{n}$ & $\%$ & & \\
\hline \multicolumn{9}{|l|}{ Usia balita pertama kali } \\
\hline \multicolumn{9}{|l|}{ diberikan MP-ASI : } \\
\hline 6 bulan & 10 & 24,4 & 31 & 75,6 & 41 & 42,3 & 0,012 & 1,6 \\
\hline$>6$ atau $<6$ bulan & 29 & 51,8 & 27 & 48,2 & 56 & 57,7 & & \\
\hline \multicolumn{9}{|c|}{$\begin{array}{l}\text { Bentuk MP-ASI yang diberikan } \\
\text { sesuai usia balita : }\end{array}$} \\
\hline Tepat & 32 & 39,0 & 50 & 61,0 & 82 & 84,5 & 0,788 & 1,1 \\
\hline Tidak Tepat & 7 & 46,7 & 8 & 53,3 & 15 & 15,5 & & \\
\hline \multicolumn{9}{|c|}{$\begin{array}{l}\text { Frekuensi MP-ASI diberikan } \\
\text { dalam sehari : }\end{array}$} \\
\hline Tepat & 28 & 36,4 & 49 & 63,6 & 77 & 79,4 & 0,208 & 1,4 \\
\hline Tidak Tepat & 11 & 55,0 & 9 & 45,0 & 20 & 20,6 & & \\
\hline \multicolumn{9}{|c|}{$\begin{array}{l}\text { Jumlah MP-ASI diberikan dalam } \\
\text { tiap kali makan : }\end{array}$} \\
\hline Tepat & 19 & 32,8 & 39 & 67,2 & 58 & 59,8 & 0,107 & 1,4 \\
\hline Tidak Tepat & 20 & 51,3 & 19 & 48,7 & 39 & 40,2 & & \\
\hline
\end{tabular}




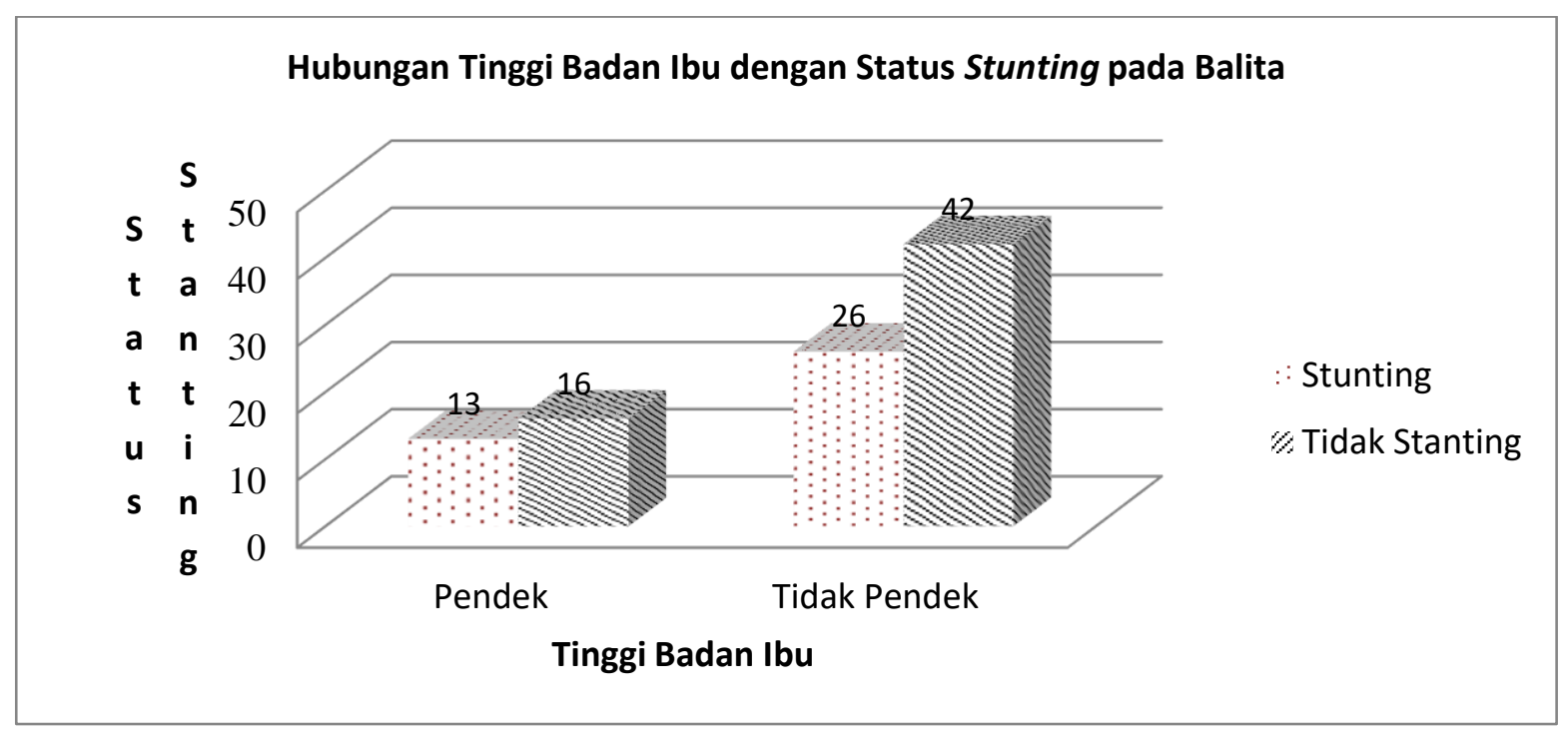

Gambar 1. Hubungan Tinggi Badan Ibu dengan Status Stunting pada Balita

Sebesar $15,5 \%$ balita dalam penelitian ini memiliki riwayat berat badan lahir rendah. Bayi berat lahir rendah (BBLR) mengindikasikan adanya kekurangan zat gizi, pola makan yang buruk dan makanan yang tidak berkualitas serta seringnya menderita penyakit infeksi dalam 1000 hari pertama kehidupannya. Hal tersebut berhubungan dengan kondisi ibu selama hamil kekurangan gizi, usia ibu lebih dari 35 tahun dan kurang dari 20 tahun serta jarak kehamilan dan persalinan terlalu dekat ${ }^{19}$.

Balita yang memiliki berat lahir rendah lebih berisiko untuk tumbuh stunting dibandingkan balita yang memiliki berat lahir normal ${ }^{20}$. Akan tetapi apabila balita tersebut mendapat asupan yang memadai serta kondisi lingkungan mendukung pertumbuhan dan perkembangan anak balita maka balita yang terlahir dengan BBLR tidak akan mempengaruhi pertumbuhan anak ${ }^{21}$.

Distribusi hubungan tinggi badan ibu dengan status stunting balita dapat dilihat pada Gambar 1 . Gambar 1 menunjukkan bahwa ibu yang tinggi badannya pendek masih cenderung melahirkan balita stunting sebanyak 13 anak (44,8\%). Hasil analisis berdasarkan uji Chi-Square menunjukkan tidak terdapat hubungan yang bermakna antara tinggi badan ibu dengan kejadian stunting pada balita usia 24-59 bulan di kecamatan Maron Kabupaten Probolinggo $(p=$ $0,704)$.

Kartikawati (2011) menyebutkan dalam penelitiannya bahwa tinggi badan sebagai faktor keturunan dari ibu, memiliki pengaruh terhadap kejadian stunting pada balita ${ }^{22}$. Menurut penelitian Mamabolo, dkk (2005) gen pembawa sifat pendek pada orang tua menyebabkan adanya kemungkinan memiliki anak stunting ${ }^{23}$. Namun apabila orang tua pendek tersebut akibat karena ada faktor masalah gizi yang dialami orang tua maka belum tentu memiliki anak pendek sehingga ibu pendek tidak memiliki berpengaruh terhadap tinggi badan anaknya ${ }^{24}$.
Hasil penelitian pemberian MP-ASI dengan kejadian stunting balita disajikan pada tabel 4 . Uji statistik MP-ASI menunjukkan hasil bahwa usia balita saat pertama kali mendapat MP-ASI memiliki hubungan signifikan dengan status stunting pada balita di wilayah kerja Puskesmas Maron. Korelasi usia balita saat pertama kali diberikan MP-ASI dengan status stunting didapatkan hasil -0,182 artinya semakin tepat usia pemberian MP-ASI pada balita, maka semakin rendah resiko terjadinya stunting.

Hasil penelitian ini membuktikan adanya hubungan antara riwayat pemberian MP-ASI dengan status stunting pada balita usia 24-59 bulan di wilayah kerja Puskesmas Maron. Nilai Odds Ratio 1,568 menandakan bahwa balita yang diberikan MP-ASI dengan tepat sesuai usia berpeluang 1,568 kali tumbuh tidak stunting dari pada balita yang diberikan MP-ASI tidak tepat.

Usia 6 bulan, pencernaan bayi sudah siap untuk menerima makanan. Menurut WHO (2010), Pemberian MP-ASI dini sebelum 6 bulan ataupun lebih dari 6 bulan dapat menyebabkan bayi kekurangan zat gizi dan akan mengalami kurang zat besi, serta mengalami tumbuh kembang yang terlambat ${ }^{2}$. Menurut hasil penelitian Widyaswari (2011), bayi yang diberi MP-ASI 6 bulan status gizinya lebih banyak normal dibandingkan pada usia 0- 3 bulan atau 4-5 bulan. Status gizi kurang pada balita bisa karena akibat pengenalan MP-ASI kurang dari 6 bulan 25. Hasil Penelitian yang mendukung dilakukan Rohmani (2010), bahwa adanya hubungan yang erat antara usia pertama pemberian MP-ASI dengan status gizi pada indek BB/U dan TB/U lemah, dengan arah hubungan yang positif, artinya semakin awal usia pemberian MP-ASI maka status gizi anak semakin buruk ${ }^{26}$.

Bentuk MP-ASI yang diberikan sesuai usia anak. Hasil uji statistik bentuk MP-ASI terhadap status stunting menunjukkan $p$-value 0,788 menandakan tidak memiliki hubungan yang signifikan. 
Penelitian yang dilakukan oleh Widyawati dkk (2016) juga menunjukkan hasil yang tidak signifikan antara bentuk MP-ASI dengan status gizi dengan nilai $p=1^{27}$. Hasil penelitian ini tidak sesuai dengan teori yang menyatakan bahwa kemampuan sistem pencernaan bayi dalam masa perkembangannya berbeda-beda sehingga bahan makanan untuk bayi disesuaikan dengan umurnya ${ }^{28}$. Pada usia 6 bulan, bentuk makanan harus dalam bentuk bubur lunak sebab enzim yang dimiliki anak untuk menghaluskan makanan masih dalam masa pembentukan.

Anak yang tidak diberi bentuk sesuai sesuai usianya akan mudah terkena diare dan berisiko dehidrasi ${ }^{29}$. Apabila kejadian diare dan dehidrasi terjadi terus-menerus maka akan berdampak pada pola pertumbuhan karena infeksi mempunyai kontribusi terhadap penurunan nafsu makan sehingga akan mempengaruhi pertumbuhan linear anak ${ }^{30}$. Keterbatasan penelitian ini, penulis tidak meneliti tentang riwayat penyakit diare, dimana diare dapat berhubungan langsung dengan kejadian stunting.

Frekuensi MP-ASI yang diberikan pada balita dalam sehari $(1 \quad x \quad 24$ jam). Ketepatan frekuensi pemberian MP-ASI pada balita non-stunting lebih besar $(63,6 \%)$ jika dibandingkan dengan balita stunting yang hanya sebesar $36,4 \%$, sedangkan $p$-value 0,208 menandakan tidak ada hubungan yang signifikan antara frekuensi pemberian MP-ASI dengan status stunting balita. Hal ini sejalan dengan penelitian yang dilakukan oleh Nurwanti dkk (2014) di Kecamatan Sedayu menunjukkan hasil bahwa frekuensi pemberian MP-ASI bukan merupakan faktor risiko kejadian stunting ${ }^{31}$. Frekuensi MP-ASI tidak memiliki hubungan yang signifikant karena meskipun frekuensi MP-ASI diberikan dengan tepat, namun jumlah dan kualitas makanan yang diberikan kurang dari standart, maka kecukupan gizi balita tidak dapat terpenuhi dan jika berlangsung dalam waktu yang cukup lama akan menyebabkan balita menjadi stunting ${ }^{18}$. Berbeda dengan penelitian Widyaswari (2011) yang menyatakan adanya hubungan frekuensi cara pemberian MP-ASI dengan status gizi (BB/TB) ${ }^{25}$

Jumlah MP-ASI yang diberikan dalam tiap kali makan. Ketepatan Jumlah MPASI yang diberikan pada balita tidak stunting lebih tinggi yaitu sebesar $67,2 \%$ dari pada balita stunting sebesar 32,8\%. Meskipun persentase lebih tinggi pada balita tidak stunting yang diberi MP-ASI dengan jumlah yang tepat, namun hasil uji statistik menunjukkan bahwa tidak ada hubungan yang signifikan. Jumlah MP-ASI yang diberikan pada balita, meskipun secara kuantitas sudah sesuai standart namun jika kualitas makanannya kurang baik atau tidak beragam, balita akan mengalami defisit terhadap zat gizi tertentu, misalnya pada anak-anak yang mengalami defisiensi vitamin A dan zink berpengaruh terhadap proses pertumbuhan linier ${ }^{32}$. Hal ini sejalan dengan penelitian yang dilakukan oleh Nurwanti dkk (2014) bahwa jumlah MP-ASI yang diberikan tidak berpengaruh dengan kejadian stunting ${ }^{31}$.

Penelitian ini memiliki kelemahan diantaranya adalah variabel yang digunakan dalam penelitian ini belum mewakili semua faktor-faktor yang mempengaruhi kejadian stunting pada balita selain itu metode pengumpulan data hanya menggunakan data kuesioner, instrumen yang digunakan kurang spesifik, misalnya menggunakan foto bentuk bahan makanan menurut golongan usia bayi saat wawancara untuk membantu menyamakan persepsi antara pewawancara dengan responden.

\section{KESIMPULAN}

Ibu pendek tidak selamanya memiliki anak pendek (stunting) meskipun ada kecenderungan pada ibu pendek melahirkan anak yang stunting, namun apabila dalam pola asuhnya baik terutama pola makan yaitu pemberian MP-ASI yang tepat, anak akan tumbuh sehat dan optimal. Hal ini karena gizi merupakan faktor utama yang mendukung terjadinya proses metabolisme di dalam tubuh. Oleh karena itu semakin banyak ibu yang memberikan MP-ASI dengan tepat, maka semakin sedikit balita yang mengalami stunting. Diharapkan bagi para ibu balita sebaiknya menghentikan pemberian makanan dan minuman selain ASI sampai balita berusia 6 bulan dan keluarga hendaknya mendukung ibu balita agar memberikan ASI yang berkualitas. Bagi petugas kesehatan disarankan agar memberikan larangan pada ibu balita dan keluarga agar tidak memberikan makanan dan minuman selain ASI sebelum balita berusia 6 bulan.

\section{ACKNOWLEDGEMENT}

Penulis mengucapkan terima kasih kepada Pihak Puskesmas Maron Kabupaten Probolinggo yang telah memberi izin penelitian dan dosen Departemen Gizi FKM UNAIR atas bimbingan dan saran yang diberikan sehingga penulisan artikel ini dapat terselesaikan.

\section{REFERENS}

1. UNICEF. Improving Child Nutrition The Achievable Imperative For Global Progress. (2013).

2. WHO. Nutrition Landscape Information System (NLIS) Country Profile Indicators: Interpretation Guide. Switzerland. (WHO Press, 2010).

3. Balitbangkes. Riset Kesehatan Dasar 2013. (Kementerian Kesehatan Republik Indonesia, 2013).

4. Balitbangkes. Laporan Riset Kesehatan Dasar Tahun 2010. (Kementerian Kesehatan Republik Indonesia, 2010).

5. Sekretariat, W. P. R. 100 Kabupaten/Kota Prioritas untuk Intervensi Anak Kerdil (Stunting). 1, (2017).

6. WHO. Childhood Stunting : Context, Causes and Consequences WHO Conceptual framework. 9, (2013).

7. UNS/SCN. Maternal Nutrition and the Intergenerational Cycle of Growth Failure Sixth Report on the World Nutrition Situation. (2013).

8. Sumarmi, S. Maternal Short Stature and neonatal stunting: An Inter-Generational Cycle of Malnutrition. in conference 265-272 (2016). 
9. Bahmat, D., Bahar, H. \& Jus'at, I. Hubungan Asupan Seng, Vitamin A, Zat Besi dan Kejadian pada Balita (24-59 Bulan) dan Kejadian Stunting di Kepulauan Nusa Tenggara (RISKESDAS 2010). 1-14 (2010).

10. Kemenkes RI. Petunjuk Teknis Penggunaan Buku Kesehatan Ibu Dan Anak. (Departemen Kesehatan Republik Indonesia, 2015).

11. Budiman \& Riyanto. Kapita Selekta Kuesioner Pengetahuan dan Sikap dalam Penelitian Kesehatan. (Salemba, 2013).

12. Mubarak, W., Chayatin, N., Rozikin, K. \& Supradi. in Graha Ilmu (2007).

13. Rahmawati, A., Bahar, B. \& Salam, A. in 1-16 (Program Studi Ilmu Gizi Fakultas Kesehatan Mayarakat Universitas Hasanuddin, 2012).

14. Amin, N. A. \& Julia, M. Faktor Sosiodemografi dan Tinggi Badan Orang Tua serta Hubungannya dengan Kejadian Stunting pada Balita Usia 6-23 Bulan. J. Gizi dan Diet. Indones. 2, 170-177 (2014).

15. Fikawati, S., Syafiq, A. \& Veratamala, A. Gizi Anak dan Remaja. (PT RAJAGRAFINDO PERSADA, 2017).

16. Nadiyah, Briawan, D. \& Martianto, D. Faktor Resiko Stunting Pada Anak Usia 0-23 Bulan di Provinsi Bali, Jawa Barat, dan Nusa Tenggara Timur. Gizi dan Pangan 9, 125-132 (2014).

17. Purwaningrum, S. \& Wardani, Y. Hubungan Antara Asupan Makanan dan Status Kesadaran Gizi Keluarga Dengan Status Gizi Balita Di Wilayah Kerja Puskesmas Sewon Bantul. J. Kesmas 6, 190-202 (2012).

18. Nasikhah, R. \& Margawati, A. Faktor Risiko Kejadian Stunting pada Balita Usia 24-36 bulan di Kecamatan Semarang Timur. J. Nutr. Coll. Undip 1, 176-184 (2012).

19. Huda, N. \& K, H. Aplikasi Asuhan Keperawatan Berdasarkan Diagnosa NANDA NIC-NOC. (Media Action, 2013).

20. Simanjuntak, E. Hubungan Riwayat Status Kesehatan Bayi dan Status Gizi Ibu Hamil Terhadap Kejadian Stunted Pada Anak Usia 12-24 Bulan di Wilayah Kerja Puskesmas Mersam Kabupaten Batang Hari Tahun 2015. Sci. J. 3, 222-230 (2015).

21. Aridiyah, F. O., Rohmawati, N. \& Ririanty, M. Faktor-faktor yang Mempengaruhi Kejadian Stunting pada Anak Balita di Wilayah Pedesaan dan Perkotaan ( The Factors Affecting Stunting on Toddlers in Rural and Urban Areas ). 3, (2015).
22. Kartikawati. Hubungan Tinggi Badan Ibu dengan Kejadian Stunting Pada Balita Usia 24-59 Bulan. Keperawatan dan Kebidanan Aisyiyah 10, 15-24 (2011).

23. Mamabolo, R. L., Alberts, M., Steyn, N. P., Waal, H. A. D. De \& Levitt, N. S. Prevalence and Determinants of Stunting and Overweight in 3year-old black South African Children Residing in the Central Region of Limpopo Province, Prevalence and determinants of stunting and overweight in 3-year-old black South African children residi. Public Health Nutr. 8, 501-508 (2014).

24. Hanum, F., Khomsan, A. \& Heryatno, Y. Hubungan asupan gizi dan tinggi badan ibu dengan status gizi anak balita. J. Gizi dan Pangan 9, 1-6 (2014).

25. Widyaswari, R. Hubungan Waktu Pengenalan Makanan Pendamping ASI dengan Status Gizi pada Bayi usia 6-24 bulan di Kecamatan Banjarsari Surakarta. (2011).

26. Rohmani, A. Pemberian Makanan Pendamping ASI (MP-ASI) pada Anak Usia 1-2 Tahun di Kelurahan Lamper Tengah Kecamatan Semarang Selatan, Kota Semarang. in Prosiding Seminar nasional Unimus (2010).

27. Widyawati, Febry, F. \& Destriatania, S. Analisis Pemberian MP-ASI dengan Status Gizi pada Anak usia 12-24 Bulan di Wilayah Kerja Puskesmas Lesung Batu, Empat Lawang. IImu Kesehat. Masy. 7, 139-149 (2016).

28. Proverawati, A. \& Erna, K. Ilmu Gizi untuk Keperawatan dan Gizi Kesehatan. (Muha Medika, 2011).

29. Pakhri, A., Lestari, retno S., Suaib, F. \& Suhardi, D. Gambaran Pola Pemberian Makanan Pendamping ASI dan Status Gizi pada Balita Usia 6-24 Bulan di Desa Bonto Bunga Kabupaten Maros. Media Gizi Pangan XIX, 41-48 (2015).

30. Welasasih, B. D. \& Wirjadmadi, R. B. Beberapa faktor yang berhubungan dengan status gizi balita stunting. Indones. J. Public Heal. 8, 99-104 (2012).

31. Nurwanti, E., Hildagardis \& Alit, G. Praktik pemberian makanan pendamping ASI ( MP-ASI) bukan faktor risiko kejadian stunting pada anak usia 6-23 bulan. Gizi dan Diet. Indones. 2, 126139 (2014).

32. Adriani, M. Pengaruh seng pada suplementasi vitamin A dosis tinggi terhadap status infeksi dan pertumbuhan linier balita. (Airlangga Surabaya, 2009). 